\title{
Role Closed Incision Negative Pressure Therapy in the Management of Keystone Flap in Lower Limb Defect
}

\section{Neljo Thomas ${ }^{1}$, Ravi Kumar Chittoria ${ }^{2 *}$, K Sriharsha Reddy ${ }^{1}$}

${ }^{1}$ Senior Resident, Department of Plastic Surgery, Jawaharlal Institute of Postgraduate Medical Education and Research (JIPMER), Puducherry, India-605006

${ }^{2} \mathrm{Head}$ of IT Wing and Telemedicine, Department of Plastic Surgery \& Telemedicine, Jawaharlal Institute of Postgraduate Medical Education and Research (JIPMER), Puducherry, India-605006

Correspondence to: Ravi Kumar Chittoria, Head of IT Wing and Telemedicine, Department of Plastic Surgery \& Telemedicine, Jawaharlal Institute of Postgraduate Medical Education and Research (JIPMER), Puducherry, India-605006.

Received date: February 23, 2022; Accepted date: March 04, 2022; Published date: March 11, 2022

Citation: Thomas N, Chittoria RK, Reddy KS (2022) Role Closed Incision Negative Pressure Therapy in the Management of Keystone Flap in Lower Limb Defect. J Med Res Surg 3(1): pp. 15-18. doi: 10.52916/jmrs224070

Copyright: (C2022 Thomas N, et al. This is an open-access article distributed under the terms of the Creative Commons Attribution License, which permits unrestricted use, distribution and reproduction in any medium, provided the original author and source are credited.

\section{ABSTRACT}

The keystone flap is a new flap design that has been added to the arsenal of cosmetic surgeons. The keystone flap is a type of flap that can be used to close soft tissue abnormalities using the local skin. It can be employed in a variety of situations. In the care of a keystone flap to repair a deficiency over the lower limb defect following a road traffic accident, we used closed incision negative pressure therapy.

\section{Keywords:}

Keystone flap, Closed incision negative pressure wound therapy, Lower limb defect

\section{Introduction}

Negative pressure wound therapy has changed the way of managing acute and chronic wounds [1,2]. Usually after primary closure of the wound, the incision site is covered with an occlusive or semi-occlusive dressing. In recent years negative pressure therapy also has been tried for wound that has been surgically closed primarily, especially in cases that are at high risk of Surgical Site Infection (SSI) [3,4]. In this article we share our experience of Closed Incision Negative Pressure Wound Therapy (ciNPWT) in keystone flap in lower limb trauma.

The keystone island flap was described by Behan in 2003. Based on fasciocutaneous perforators, the keystone island flap offers both the robust vascularity of perforator flaps and relative ease and speed of local tissue rearrangement. Other advantages of this technique include short operative time, high reproducibility, ease of use and local tissue aesthetic similarities. This technique possibly obviates the need for microsurgical procedures, additional skin grafts, and extensive operative time.

Cosmetic surgeons have added a new flap design to their toolkit: the keystone flap. The keystone flap is a type of flap that repairs soft tissue abnormalities by using the local skin. It can be applied in a variety of situations. A keystone flap that was used to correct a deficit over a lower limb malformation induced by an automobile accident was treated with closed incision negative pressure therapy.

\section{Case Report}

The research was carried out in a tertiary care hospital in south India after receiving approval from the institutional ethical council. The patient was a 19-year-old man who had been in a car accident and had a full-thickness injury to his lower limb. On post-admission day 7 , the lower limb defect was debrided, with loss of skin, subcutaneous tissue, and patellar tendon (Figure 1 ), because the wound's size would necessitate a huge rotation flap. We opted to proceed with a keystone flap for the lower limb defect.

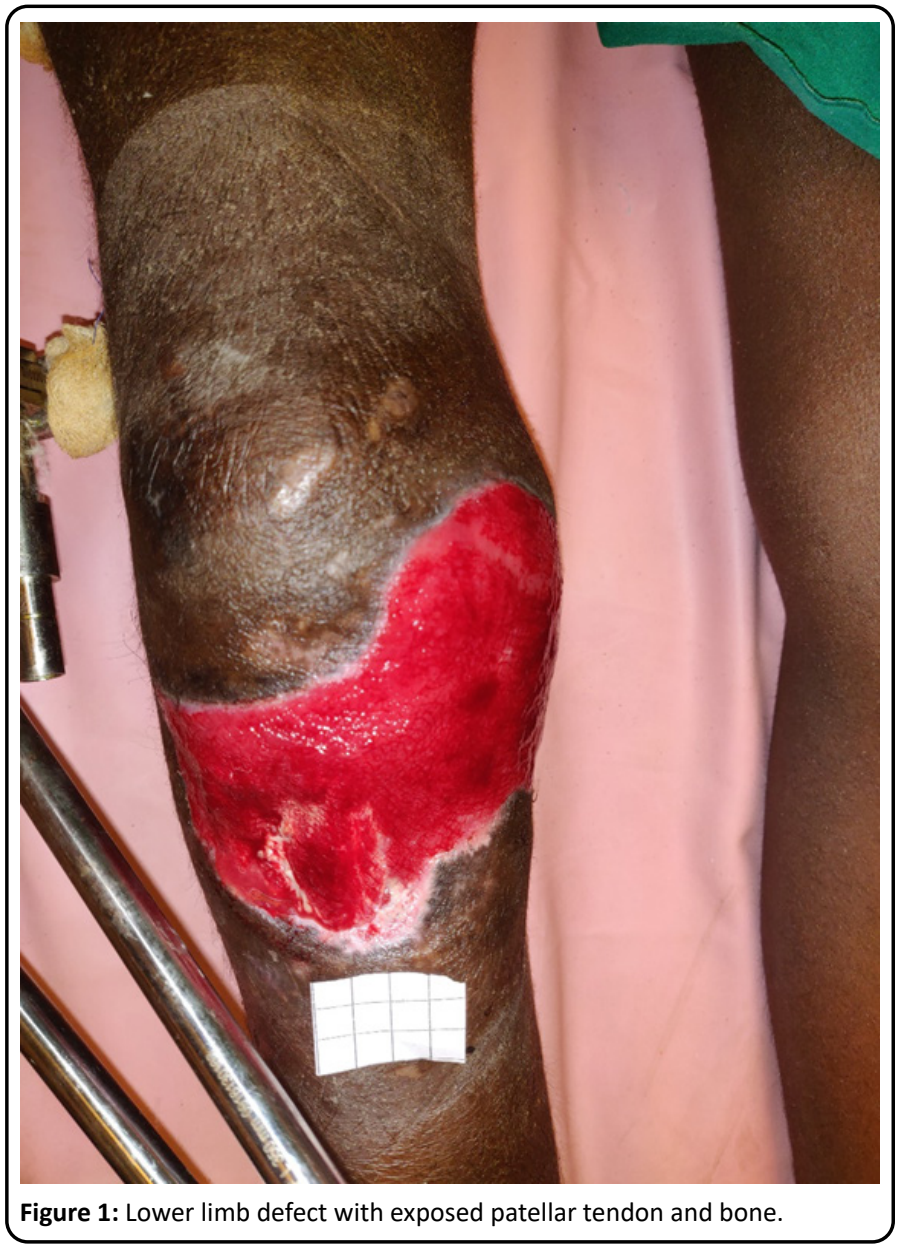

Flap Planning and Design

The length and width of the defect are measured intraoperatively after excision or debridement. There's also a remark about the maximum width. The flap donor location was chosen as the side of the defect with the most tissue laxity, and a type 2 keystone flap was planned (Figure 2 and 2a-2c). One side of the elliptical 
defect acts as the inner arc of the keystone, and an incision at 90 degrees at either end of the ellipse meets the curvilinear line of the flap outer edge. The flap's width is the same as the defect's width. The length of the flap is determined by the length of the elliptical excision.

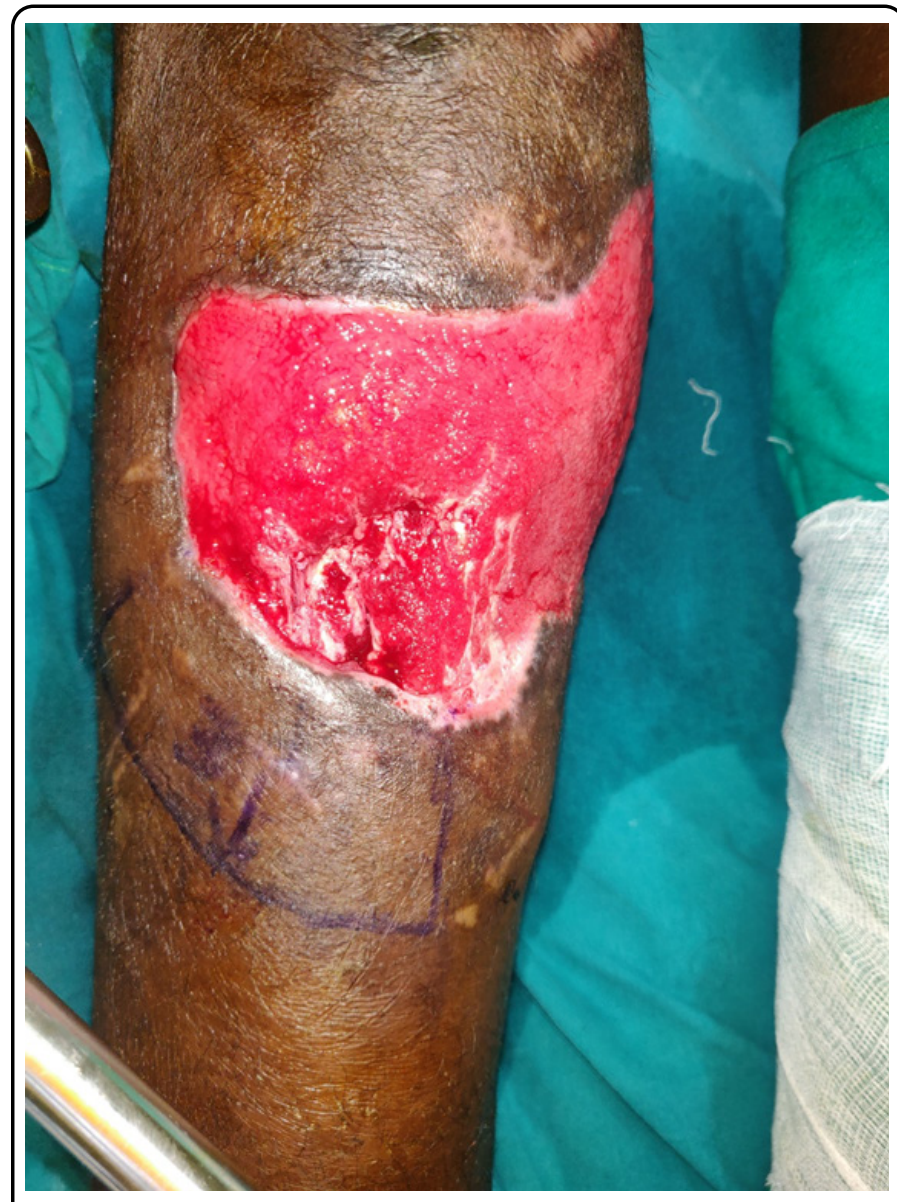

Figure 2: Lower limb defect with exposed patellar tendon and bone.

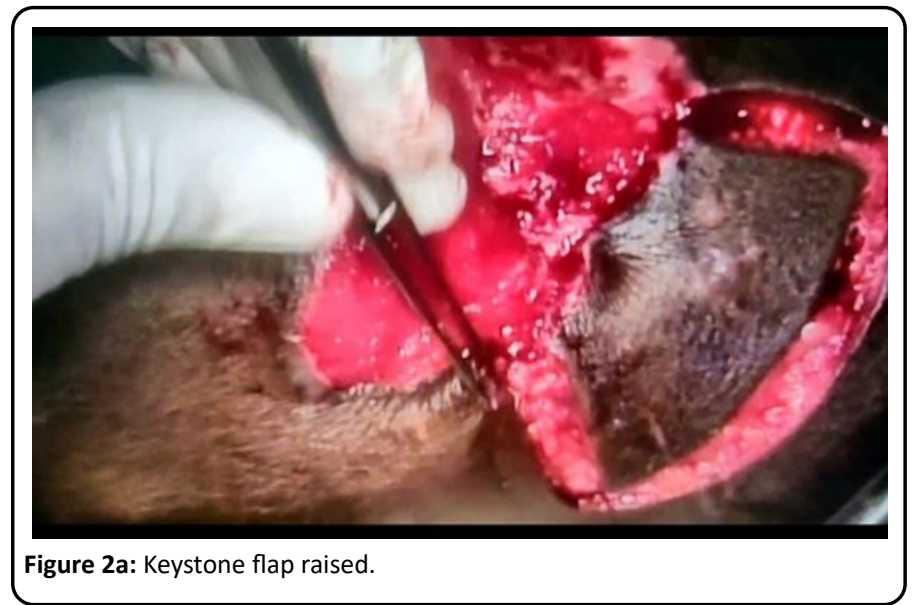

\section{Surgical Procedure}

As previously marked, an incision was made all the way along the flap's edge. The incision was deepened until it reached deep fascia, which was divided all the way around the outside border. If there is any tension in the suture line, minimal undermining was done on the other side of the defect. The initial stitch was placed in the centre of the flap, where the most strain exists. The remaining flap was sutured to the defect, the ' $Y$ ' limb was
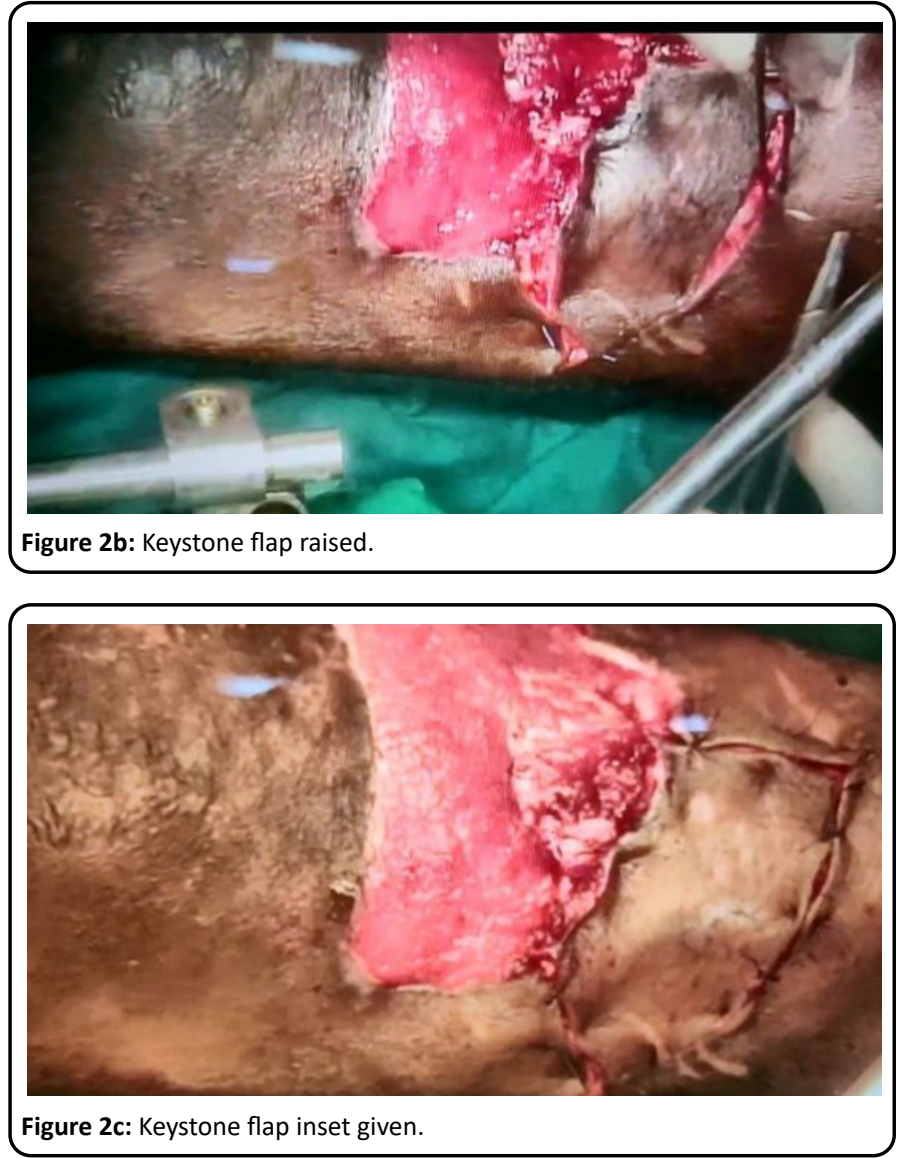

closed, and the rest of the flap on the outside border was closed using normal procedure, and closed incision wound therapy was used to heal the wound (Figure 3). Because the patient was at such a high risk of SSI, it was decided to use a tailored NPWT. A sterile sponge of the proper size was used. A suction tube with several holes of a small calibre was passed through it. On a closed incision site, a single layer of non-adherent gauze was applied. On the incision site, the sponge with the suction tube in place was put. A translucent occlusive dressing that adhered to the skin was applied (Figure 4). For seven days, a steady negative pressure of $100 \mathrm{~mm} \mathrm{Hg}$ was applied. Every day, the patient was checked for any signs of infection in the system. Every day, a clear dressing was checked for any signs of soakage, erythema, localised pain, or edoema. After 7 days, the dressing was removed and the surgical site was examined. The wound healed without incident (Figure 5).The keystone flap can be successfully used in difficult-to-mould areas like the lower limb defect and utilize the local tissue available.

\section{Discussion}

A road traffic collision is a serious injury that results in fullthickness tissue loss. The extent of harm is determined by the tissue's resistance to electric flow. Depending on the size of the defect, tiny defects can be closed primarily, moderate to medium defects require locoregional flaps, and large defects may require free flaps such as latissimus dorsi, parascaplar flaps, and others. It has the advantages of being single-staged and providing consistent coverage with well-vascularized tissues $[5,6]$. The reconstruction that demands the use of gastrocnemius, soleus muscle flaps, and reverse sural flaps is usually very complex and challenging. Unlike the propeller flap, 


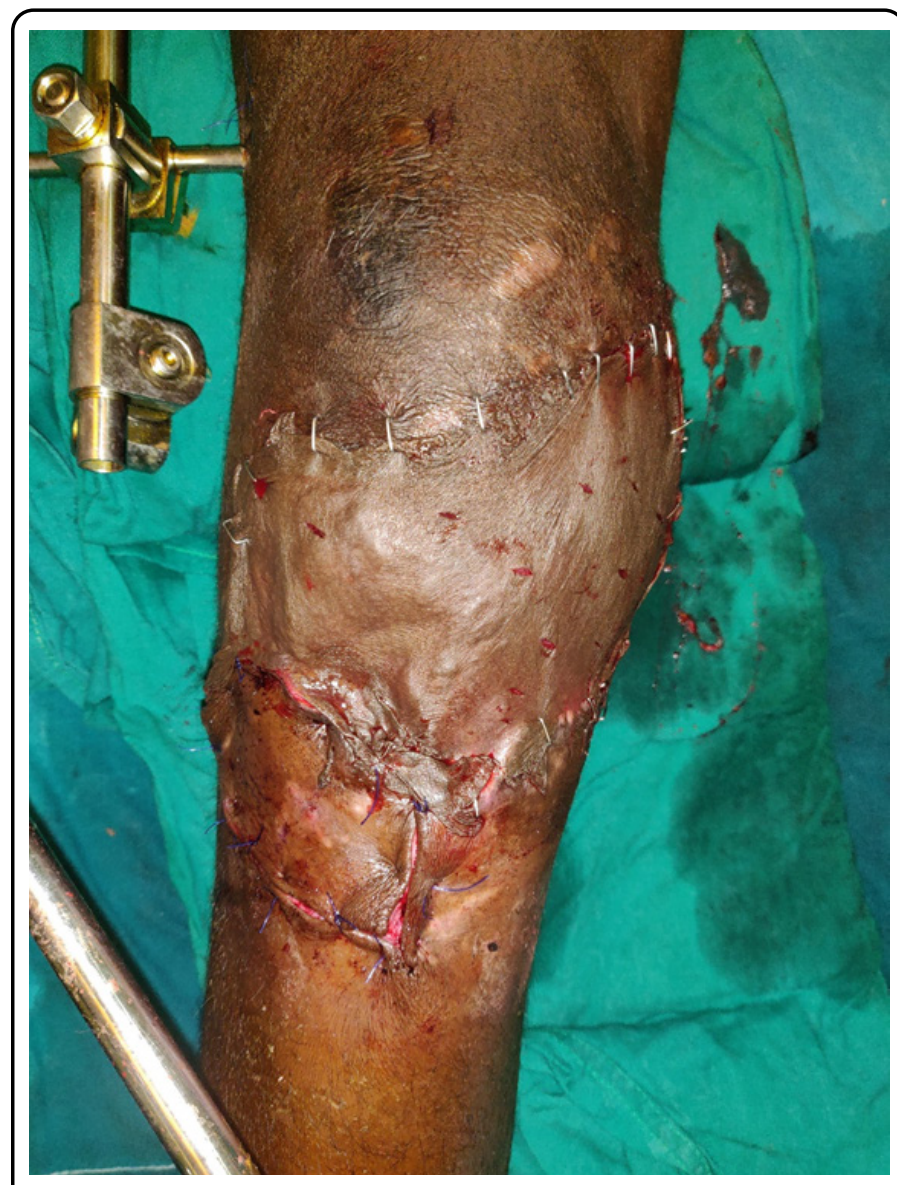

Figure 3: Keystone flap-type 2 done on the patient.

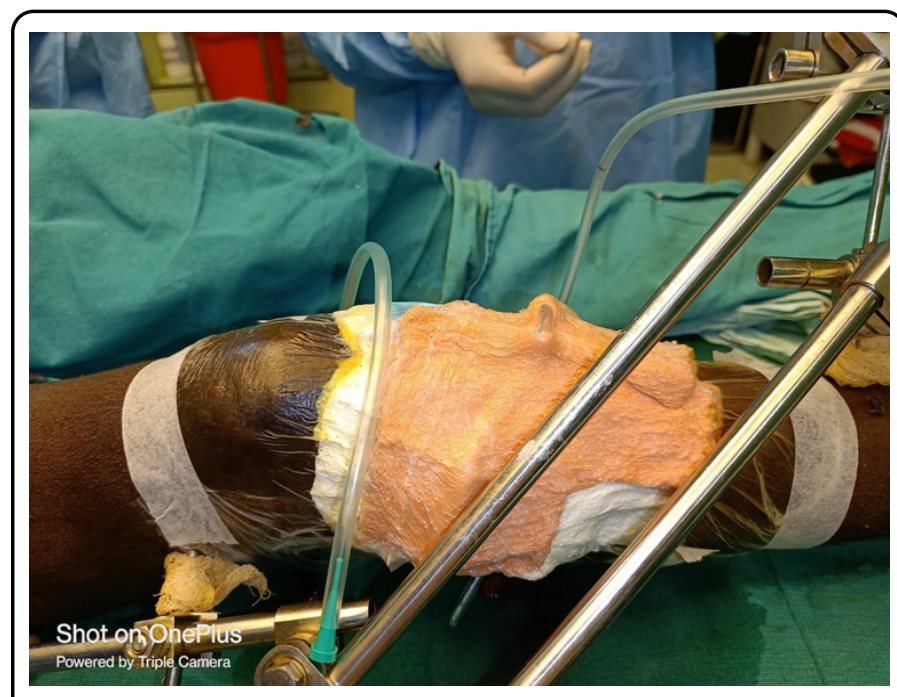

Figure 4: Keystone flap after 2 days.

the muscle flap can provide enough bulk to obliterate dead space, minimizing the risk for potential infection. The reverse sural flap is an important option to cover the heel defect when microsurgery is not feasible.

Behan was the first to explain keystone flaps, and they were used in this case as well [7]. The keystone flap is made up of two V-Y advancement flaps that face each other. Because of the mobility of these advancement flaps, additional tissue next to the defect is available to provide the primary approximation of skin margins. Any superficial/deep venous structures or

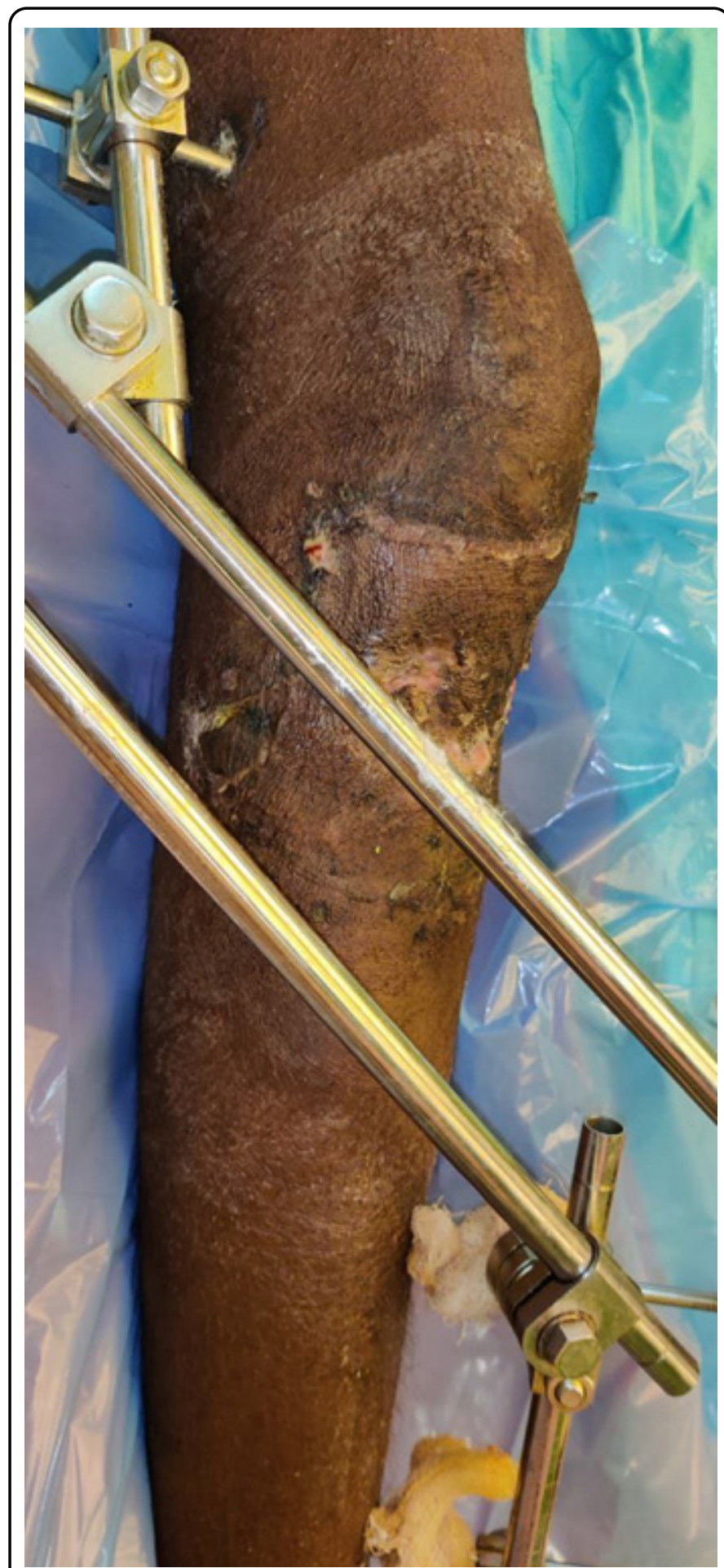

Figure 5: Keystone flap after complete healing.

cutaneous nerves are included in the construction of the flap [8].

Negative-pressure wound vacuum therapy is a well-known treatment for open surgical incisions that have become infected or have broken down. It has recently been the subject of new research on its use in closed surgical sites. Gomoll et al. published their results using a similarly modified incisional dressing in 2006, which was the first publication on Closed Incisions Employing NPWT (ciNPT). Various mechanisms for NPWT have been proposed [9]. 


\section{Macroscopic Effects of NPWT}

- Creates and maintains a moist wound environment, shortens time to wound closure

- Reduces wound oedema and reduces seroma formation

- Stimulates wound contracture through macro deformation

- NPWT stabilizes healing tissues through a bolstering Effect

- Provides oppositional forces to both superficial and deeper healing tissues

- $\quad$ Reduces size and complexity of the healing wound

\section{Microscopic Effects of NPWT}

- Increased expression of VEGF, IL-8 VEGF gradient increases toward the wound

- Vigorous angiogenesis in a parallel fashion, oriented toward the wound compared to fewer tortuous new vessels observed in controls

- Stimulates cell proliferation through micro-deformation

- Decreases local blood flow in those tissues in closest proximity to the ROCF

- Changes the colonizing flora of the wound, may increase or have no effect on overall bacterial load

- Increased neovascularization

There is a commercially available device for ciNPWT. These devices are expensive for routine use in hospitalized patients. We have used a simple way of applying input cost-effectively.

Vascularity is more significantly reliant on the lower limb defect [10]. The posterior larger curvature of the flap can be incised through the aponeurosis if the lateral incisions are made superficial to the aponeurosis in the subcutaneous layer. This combination of incisions allows for progression while maintaining perfusion on the side. The hairline is not affected by the keystone flap since it is closed at the posterior greater curve, unlike other local flaps. It does not require undermining, unlike most local skin flaps, and all fasciocutaneous and musculocutaneous perforators are preserved in the subcutaneous base underneath.

\section{Conclusion}

We have used ciNPWT in keystone flap in the management of lower limb trauma and have found it to be useful. However, this is a single case report and needs a multicentric randomised control trial to be brought into clinical practice.

\section{Conflict of Interest}

The authors report no conflict of interest.

\section{Funding}

No funding or grant support.

\section{References}

1. Agarwal A (2019) Management of Closed Incisions Using Negative-Pressure Wound Therapy in Orthopedic Surgery. Plast Reconstr Surg 143(1S Management of Surgical Incisions Utilizing Closed-Incision Negative-Pressure Therapy): pp. 21S-26S.

2. Jeyakumar $P$, Hussain AT, Ahamed AR (2018) Reconstruction of Extensive Post-Electric Burn Lowerlimb defect Defects With Exposed Bones-A Study of 12 Cases. Ann Plast Surg 81(1): pp. 39-44.

3. Stuckey JG Jr (1963) The surgical management of massive electrical burns of the lower limb defect. Plast Reconstr Surg 32: pp. 538-543.

4. Srivastava JL, Biswas G, Narayan RP, et al. (1993) Chronically exposed calvarium following electrical burns. Burns 19: pp. 138-141.

5. Lesavoy MA, Dubrow TJ, Schwartz RJ, et al. (1993) Management of large lower limb defect defects with local pedicle flaps. Plast Reconstr Surg 91: pp. 783-790.

6. Chicarilli ZN, Ariyan S, Cuono CB (1986) Single-stage repair of the complex lower limb defect and cranial defects with the free radial forearm flap. Plast Reconstr Surg 77: pp. 577-585.

7. Behan FC (2003) The keystone design perforator island flap in reconstructive surgery. ANZ J Surg 73(3): pp. 112-120.

8. Pelissier P, Gardet H, Pinsolle V, et al. (2007) The keystone design perforator island flap. Part II: clinical applications. J Plast Reconstr Aesthet Surg 60(8): pp. 888-891.

9. Hyldig N, Birke-Sorensen $H$, Kruse $M$, et al. (2016) Metaanalysis of negative-pressure wound therapy for closed surgical incisions. Br J Surg 103(5): pp. 477-486.

10. Desai SC, Sand JP, Sharon JD, et al. (2015) Lowerlimb defect reconstruction: an algorithmic approach and systematic review. JAMA Facial Plast Surg 17(1): pp. 56-66. 